\title{
25 anys de recerca en didàctica de la llengua
}

\author{
Anna Camps \\ Universitat Autònoma de Barcelona, Espanya
}

(Article rebut el 16 de març del 2017; acceptat el 17 de març del 2017; versió final 27 d'abril del 2017) DOI: http://dx.doi.org/10.5565/rev/jtl3.721

\begin{abstract}
Resum
L'article es deriva de la conferència inaugural del Màster de Recerca en Educació, dictada el 19 de gener de 2017 a la Facultat de Ciències de l'Educació, Universitat Autònoma de Barcelona, en el marc de les celebracions pel 25 aniversari de la creació d'aquesta facultat.
\end{abstract}

Paraules clau: Les didàctiques específiques; usos lingüístics; textos expositius; textos explicatius; l'activitat metalingüística

\section{Resumen}

El artículo se deriva de la conferencia inaugural del Máster de Investigación en Educación, dictada el 19 de enero de 2017 en la Facultad de Ciencias de la Educación, Universidad Autónoma de Barcelona, en el marco de las celebraciones por el 25 aniversario de la creación de esta facultad.

Palabras clave: Las didácticas específicas; usos lingüísticos; textos expositivos; textos explicativos; la actividad metalingüística

\begin{abstract}
This article is derived from the inaugural conference of the Master's Degree in Education Research given on January 19, 2017 in the Faculty of Education Sciences, Autonomous University of Barcelona, within the framework of the year-long celebrations for the 25th anniversary of the faculty.
\end{abstract}

Keywords: Specialized teaching; Language use; Expository texts; Explanatory texts; Metalinguistic activity

\section{Una mica d'història}

Celebrem els 25 anys de creació de la Facultat de Ciències de l'Educació de la Universitat Autònoma de Barcelona (UAB), l'any 1992. Deu anys abans (1982) s'havia publicat la Llei de reforma universitària (LRU). En el marc d'aquesta llei es van crear els nous departaments universitaris entre els quals els de Didàctiques específiques, prèvia inclusió de la Didàctica de la Llengua i la Literatura en el catàleg d'àrees de coneixement del Consejo de Universidades (BOE 26/10/1984). 
Les primeres passes del Departament de Didàctica de la Llengua i la Literatura de la UAB

En el moment de la seva creació cap dels professors que formàvem part del Departament de Didàctica de la Llengua i la Literatura de la UAB érem doctors (no calia ser-ho per fer de professor a les escoles de Magisteri) i gairebé tots érem el que se'n deia "no numeraris" (professors sense contracte fix, que no eren funcionaris). A la UAB, universitat de nova creació (a començaments dels anys 70), provenien de l'ensenyament primari i secundari i molts havien participat activament en la renovació pedagògica durant els darrers anys del franquisme. En la majoria dels departaments homòlegs a les altres universitats catalanes i espanyoles també hi predominava el professorat sense tesi i bastants no numeris (algunes de més antigues, com la de Barcelona, tenien una situació una mica millor). Tampoc es van crear departaments d'aquesta àrea a totes les universitats. Depenent de les diverses situacions, en algunes, els professors que impartien didàctica van integrar-se en departaments de filologia 0 de pedagogia. Cal tenir present que, en la majoria d'universitats, a diferència de la $\mathrm{UAB}^{1}$, no hi havia assignatures de didàctiques específiques sinó que els continguts didàctics depenien de les assignatures de continguts corresponents; per exemple: "Lengua española y su didáctica", "Literatura española y su didáctica" etc. Però, en constituir-se els departaments de didàctica de la llengua també hi van entrar alguns professors i professores que n'eren de llengües, catalana, castellana, francesa o anglesa i que mai no havien treballat en el camp de la didàctica ni tenien experiència docent en els nivells d'Educació Primària o Secundària.

Val a dir que les exigències actuals de la carrera universitària fan difícil la captació de professorat amb experiència docent en altres nivells educatius (però aquest no és el tema que ara ens ocupa). En aquell moment, doncs, hi havia molta feina per fer.

La primera de totes era delimitar què s'entenia com a àrea de Didàctica de la Llengua. La idea més comuna --no entre molts dels que ja impartíem didàctica des de feia uns anys, però sí en els entorns universitaris de Pedagogia o de Filologia- era que la didàctica consistia només en l'aplicació dels continguts propis de les àrees filològiques i lingüístiques i aquesta aplicació es regia per principis propis de la recerca pedagògica que considerava aspectes generals del fet educatiu sense tenir en compte les especificitats i les característiques del coneixement que s'impartia. La delimitació de l'àrea de coneixement era tema de debat $\mathrm{i}$ d'elaboració no únicament en el nostre país, sinó també a d'altres com per exemple França i Suïssa, amb els quals el Departament de Didàctica de la Llengua i la Literatura de la UAB tenia molta relació. 
La segona tasca, no en ordre cronològic sinó del tot simultània, era la d'endegar recerca que ajudés en aquesta delimitació i definició. Les primeres tesis doctorals van contribuir-hi i van ser fundacionals en els seus dominis respectius i han estat a la base de les línies de recerca i dels grups del departament de la UAB.

Val a dir que no es pogueren presentar en departaments de didàctica perquè encara no hi havia doctorats en aquesta àrea. Aquesta circumstància va ser la causa que professors d'algunes universitats fessin tesis sobre temes de literatura o de llengua propis dels estudis de filologia la qual cosa alentia la consolidació de la Didàctica de la Llengua i la Literatura com $\mathrm{a}$ àrea $\mathrm{amb}$ reconeixement acadèmic consolidat.

La tercera tasca, fruit en part de les dues primeres, sense les quals aquesta tercera no hauria estat possible, va ser la creació de doctorats específics en Didàctica de la llengua i la literatura (i en didàctiques específiques diverses), no en totes les universitats, però sí en les que havien arribat a tenir una infraestructura acadèmica mínima suficient. El primer curs de doctorat de Didàctica de la Llengua i la Literatura de la UAB així com el de Ciències Social van començar el curs 1995-96.

Paral-lelament a tot això el professorat es va haver d'homologar, és a dir, fer oposicions per poder ser professor d'universitat. Ara a molts dels que llegeixin això no trobaran estrany que la majoria de professors fossin "no numeraris" perquè la situació actual de la universitat espanyola és realment crítica en aquest aspecte. En aquells moments, després de proclamada la LRU les oposicions, va ser l'únic camí possible, malgrat que veus des de l'esquerra defensaven un model no funcionarial, sinó de contracte laboral (no, per descomptat, de precarietat com el d'ara). Però les coses van ser així. Per això, també en aquells anys, molts professors es van veure implicats en concursos per accedir a una plaça de professor numerari, primer de TEU i, a mesura que es feien les tesis doctorals, de TU. Finalment el 1998 es va crear la primera plaça de catedràtic (CU) de Didàctica de la Llengua a la UAB, que es va ocupar el 1999. A la resta d'Espanya ja n'hi havia cinc, una d'elles a la Universitat de Barcelona.

En fi, aquests són els orígens dels Departaments de Didàctiques específiques a les universitats espanyoles. Però no és d'això del que voldria parlar principalment tot i que reprendrem alguns aspectes mencionats, especialment el que fa referència a la delimitació de l'àrea. 


\section{5 anys de recerca en Didàctica de la llengua i la Literatura}

Dues consideracions prèvies:

Primer, parlaré de la recerca en didàctica de la L1 (i la L2 en comunitats on hi ha dues llengües oficials). No em referiré a les LE ni tampoc amb detall a la didàctica de la Literatura. Segon, cal preguntar: de què parlem, quan parlem de recerca? Les pràctiques innovadores d'aula, que es donen a conèixer? La recerca formalitzada d'entorns acadèmics? Parlaré d'aquesta darrera, tot i que considero que aportacions clau a l'ensenyament de la llengua (de la lectoescriptura, per exemple) no sorgeixen en aquests entorns, per exemple el treball de Celestin Freinet a l'aprenentage aprendizaje de la lectura i l'escriptura.

\section{a) Què caracteritza la recerca en Didàctica de la Llengua}

La primera cosa que cal destacar és que no tota la recerca universitària sobre l'aprenentatge de la llengua es fa des de Departaments de Didàctica. Ni tampoc es pot dir que tota la recerca que es fa en els Departament de DL sigui pròpiament de didàctica. En parlarem.

Els anys 2006 a 2009 el grup GREAL de la UAB va coordinar un projecte que hauria pogut ser realment important. Es va organitzar una Xarxa de grups de recerca que investigaven sobre ensenyament de llengües, la Xarxa LLERA. La va finançar el Departament d'Educació de la Generalitat de Catalunya. En formaven part 17 grups de recerca sobre ensenyament de llengües de set universitats catalanes. L'objectiu que es va proposar fou el de posar en contacte diferents línies de recerca a fi de concentrar esforços i de rendibilitzar el treball que els grups dispersos duien a terme. Només va durar 3 anys. Dificultats de tota mena van fer difícil la seva continuïtat, especialment la reducció primer i la supressió després del finançament (la crisi ja ens havia envaït). El resultat de les primeres jornades conjuntes va constituir un panorama del que es feia en recerca sobre ensenyament de llengües a Catalunya. Queda recollit en el llibre "Mirades i veus"(Camps i Millan, 2008).

En el panorama que es dibuixa en la publicació esmentada queda patent el que hem dit: no tota la recerca sobre ensenyament de llengües es fa des dels departament de didàctica. Investiguen també sobre aquet tema departament de Filologies diverses, de Psicologia i també algun de Pedagogia.

Al costat d'això, en els departament de didàctica es duen a terme algunes recerques que es podria discutir si són pròpiament didàctiques. Per exemple es fan tesis sobre temes de literaris, de sociolingüística, etc. Ens hauríem de preguntar, doncs, quines són les característiques pròpies de la recerca en Didàctica de la Llengua i la Literatura. 
Cal tenir també present que en el món anglosaxó no es parla de didàctica en el món de la recerca. La investigació sobre ensenyament de llengües es fa des d'àrees diverses, algunes que s'han fet gairebé autònomes com són les de lectura i d'escriptura, lligades més aviat a la psicologia i la retòrica. Les diverses estructures de la recerca acadèmica en cada país condicionen en gran part aquesta dispersió.

\section{b) Especificitat de la recerca en didàctica de la llengua}

En els anys de las creació dels departaments de didàctica es plantejava aquesta pregunta, en l'intent de definir quin n'era l'objecte de recerca, que és en definitiva el que pot delimitar un àmbit d'investigació específic. Les primeres memòries d'oposicions són il·lustratives de les dificultats d'aquesta definició. El marc teòric que s'hi dibuixava era una juxtaposició de referents de les teories lingüístiques, de les teories psicològiques i d'algunes aportacions pedagògiques, amb molt poc o cap lligam entre elles. A nivell internacional s'estava intentant elaborar un marc que donés compte de la complexitat de l'objecte de la DLL. Les aportacions de didàctics, principalment francesos, com Chevallard (1989/1991) (de la matemàtica) van centrar el debat en plantejar que l'objecte de les didàctiques específiques el constitueix la relació que s'estableix entre tres pols del que es va denominar "triangle didàctic" o "sistema didàctic": la matèria o àrea de coneixement que és objecte d'ensenyament, el discent que aprèn i el docent que ensenya i li facilita l'accés a aquest coneixement. D'altres conceptes clau que es van introduir són els de "transposició didàctica" i de "contracte didàctic" que ara no tenim temps d'explicar. Aquesta concepció inicial del sistema didàctic s'enriqueix i s'elabora $\mathrm{amb}$ aportacions diverses d'investigadors de didàctiques específiques i és especialment debatut en l'àrea de didàctica de la llengua.

A partir de la consideració d'aquest sistema com a caracterització bàsic de l'objecte de la Didàctica de la Llengua, es pot constatar que, com dèiem, no tota la recerca sobre la llengua a les aules és pot qualificar de didàctica. La sociolingüística, per exemple, s'interessa pels usos lingüístics de nens i nenes en entorns escolars, però el seu focus no és la relació entre l'ensenyament i l'aprenentatge de les llengües. En el cas de la didàctica de la llengua, quan s'analitza la comunicació a l'aula, es fa per comprendre de quina manera nens i nenes s'apropien d'uns coneixements de la llengua que intencionalment la institució docent vol ensenyar. L'objecte material, els intercanvis comunicatius de nens i nenes a les aules, és el mateix, però no ho és el seu objecte formal que en el primer cas són els usos comunicatius en 
ells mateixos i, en el segon, les relacions entre l'ensenyament i l'aprenentatge de la llengua que aquests intercanvis comunicatius poden arribar a promoure.

És clar que les fronteres entre disciplines és difusa i que, en molts casos, es fa difícil d'establir què és recerca didàctica $\mathrm{i}$ què no ho és. Tenint present a més que l'evolució d'algunes disciplines, com ara la psicologia, les ha portat a ampliar el seu camp, que inicialment se centrava en l'individu. La psicologia sociocultural, per exemple, no pot deixar de banda els contextos socials i culturals en què l'individu creix i es forma; l'entorn escolar amb tota la seva complexitat és un àmbit clau d'aquests contextos en que es desenvolupa l'aprenentatge de les llengües en la nostra societat.

\section{c) Les línies de recerca sobre ensenyament de llengües primeres i segones (no de LE)}

No hi ha cap treball actualitzat que doni compte de la recerca en DL duta a terme a Catalunya ni a l'Estat Espanyol durant aquest anys que considerem. Seria molt interessant tenir aquesta història la qual cosa ens permetria veure amb major perspectiva el lloc on som ara.

Alguns treballs parcials presentats en congressos de didàctiques especifiques, com el de Santiago de Compostela, 1992 remarcaven que el que es presentava sota l'epígraf de Didàctica de la Llengua no era pròpiament recerca sinó que eren experiències, propostes d'ensenyament o reflexions especulativo-teòriques.

Quina era la situació? En els anys 60-70, des dels estudis de Pedagogia de les universitats es van dur a terme algunes recerques en un marc teòric positivista. Per exemple sobre avaluació, sobre ensenyament programat o del tipus pre-post test. A Catalunya l'antecedent del treball d'Alexandre Galí (1928) va inspirar treballs sobre l'avaluació de l'ortografia o de la lectura. A la UB els anys 70 es va dur a terme una interessant recerca sobre l'incipient ensenyament del català a algunes escoles que es van poder considerar experimentals.

No hem d'oblidar l'important treball d'Emilia Ferreiro i Ana Teberosky, d'orientació piagetiana, sobre els conceptes dels infants sobre l'escriptura. Es va dur a terme a l'Argentina. L'impacte d'aquest treball i la necessitat de renovació en l'ensenyament infantil i primari que exigia a Catalunya la implantació de immersió lingüística van promoure un veritable canvi en l'educació infantil a Catalunya que va tenir importants repercussions a tot Espanya.

No va ser fins els anys 80 , però, que el panorama de la recerca acadèmica sobre l'ensenyament de la llengua va canviar. Els factors d'institucionalització dels departament de Didàctica de la Llengua i la Literatura hi van contribuir, però l'impuls va venir de la crisi que 
es percebia i s'experimentava des de feia temps en l'aprenentatge de la llengua a l'ensenyament primari i secundari. Els currículums de molts països (p.e. Itàlia, en aquell moment capdavantera de la renovació pedagògica; o els espanyols, resultat de la renovació que va promoure la LOGSE) van posar l'accent en la necessitat de donar prioritat a l'ensenyament de les habilitats lingüístiques: parlar, escoltar, llegir i escriure. Però la recerca formal no hi contribuïa encara.

La inquietud per millorar l'ensenyament de la lectura i l'escriptura en nivells educatius primaris i secundaris va trobar suport i guia en els treballs que investigadors nord-americans van dur a terme principalment des de departaments de Psicologia i de Retòrica.

La tesi d'Isabel Solé sobre les estratègies de lectura, elaborada i presentada en el Departament de Psicologia Evolutiva i de l'Educació de la Universitat de Barcelona el 1985 i publicada a l'any 1987 va ser la impulsora teòrica de canvis importants en l'orientació de la recerca sobre l'ensenyament de la lectura a Espanya. Posteriorment d'altres departament de Psicologia van mantenir importants línies de recerca sobre lectura, per exemple a València i a Salamanca. La idea fonamental que guiava aquest tipus d'estudis d'orientació cognitiva era la necessitat d'ensenyar estratègies de lectura (activitats abans, durant i després; ensenyament directe d'estructures textuals, etc.) per millorar la comprensió, perquè, evidentment, llegir és comprendre. La lectura ha estat objecte de recerca des d'altres enfocaments. Per exemple, alguns grups de recerca sobre la literatura infantil s'interessen per la recepció de l'obra literària (infantil i juvenil, o no), per l'estudi dels itineraris lectors, etc. Aquesta recerca uneix les aproximacions sobre els processos amb la tradició de l'estudi de la literatura per a infants i adolescents.

Ja des de la creació dels departament de didàctica l'estudi de la Literatura infantil i juvenil s'hi va integrar, no sense algunes opinions contraries que la volien incorporada a l'àrea de literatura.

Amb uns anys de diferència també l'escriptura va ser objecte de recerques d'orientació cognitiva als EEUU. L'abast de la recerca sobre escriptura va ser enorme amb nombrosos programes i centres específics i amb recerca molt diversa, des de la que es duia a terme en laboratoris fins a la lligada a l'acció a les mateixes aules. D'altra banda, l'orientació estrictament cognitiva i centrada en les estratègies de planificació, textualització i revisió dels primers estudis va ser ampliada per alguns autors a aspectes socio-cognitius, la qual cosa va enriquir la visió de la complexitat de la tasca d'escriptura. Les tècniques d'accés al pensament de l'escriptor en el curs de la tasca van permetre entrar en el mateix procés d'elaboració 
textual, superant d'aquesta manera la visió de l'escrit com una cosa tancada en ella mateixa i acabada. En aquest marc s'insereix la tesi d'Anna Camps sobre l'ensenyament de la composició escrita llegida el 1991 i publicada el 1994. El diàleg entre els components de grups d'infants que escriuen en col-laboració obren el procés d'escriptura a la possibilitat d'intervenció i, per tant, d'aprenentatge durant el procés mateix de producció textual. És la primera recerca europea que recull la veu dels aprenents en el procés de composició textual.

A partir d'aquests anys l'aprenentatge de l'escriptura serà objecte de múltiples recerques que enfoquen diversos dels aspectes implicats en aquest procés: l'ensenyament de subprocessos com la planificació i especialment la revisió, l'avaluació formativa, els contextos que incideixen en l'activitat d'escriptura, l'ús de la llengua primera i segona en el diàleg per escriure, l'escriptura acadèmica, etc.

Un dels aspectes més rellevants de la recerca sobre ensenyament de l'escriptura a Catalunya i a Espanya és que hi conflueixen i s'hi fonen dues línies d'estudi aparentment divergents, però que acaben confluint: els estudis socio-cognitius del processos redaccionals i els estudis del text i del discurs que es desenvolupen a Europa durant el segle XX. La perspectiva de la recerca sobre ensenyament de l'escriptura s'obre a la diversitat, primer dels tipus de textos que les taxonomies estructuralistes aporten i més tard de la diversitat de discursos que es generen en els intercanvis verbals dels humans relacionats amb la diversitat d'activitats que duen a terme. No es planifica de la mateixa manera un text d'opinió que un conte o que una notícia.

No n'hi ha prou a ensenyar estratègies de planificació, de revisió, etc. en elles mateixes, sinó que cal posar els alumnes en situació de producció de textos amb finalitat pròpia i ensenyar-los a adoptar les estratègies adequades i a usar els recursos lingüístics propis del tipus de discurs que s'està produint. La recerca té un camp obert a l'estudi d'aquesta diversitat a les aules i els treballs de recerca sobre l'ensenyament de l'argumentació, dels textos expositius i explicatius, de la narració, etc. serà abundant en aquests anys 90, referits a tots els nivells educatius.

Una de les línies que adquireix una gran rellevància és la recerca sobre l'escriptura acadèmica que vol donar resposta a la necessitat creixent dels universitaris de produir "papers" i de publicar per avançar en la seva carrera acadèmica. De tota manera, aquest no hauria de ser, i no és, l'únic objectiu de l'ús i l'ensenyament de l'escriptura a la universitat. Un dels camps de recerca obert és el de l'escriptura com instrument d'elaboració del coneixement que implica els estudiants (de tots els nivells educatius) en l'activitat d'aprendre, 
més enllà d'escoltar i prendre apunts. Curiosament, a diferència del que va passar amb la recerca sobre la lectura, no han estat, fins ara, els departaments de psicologia els capdavanters en recerca sobre l'escriptura, que ha tingut el desenvolupament més important en departaments de didàctica.

L'ensenyament inicial de la lectoescriptura ha constituït un camp en certa manera independent de les orientacions predominants en lectura i en escriptura de què hem parlat. Ara no en parlarem.

Fins ben endavant del s. XX la recerca sobre les habilitats lingüístiques es mantenien més aviat separades: sobre lectura, més o menys relacionada amb la literatura; sobre escriptura, sobre primer aprenentatge de la lectoescriptura; sobre llengua oral. La recerca sobre ensenyament de la gramàtica es pot dir que havia desaparegut, com va desaparèixer la gramàtica en alguns currículums de primària, per exemple aquí a Catalunya.

De tota manera algunes publicacions i algunes propostes ja s'orientaven a considerar les interrelacions entre escriptura i lectura i entre lectura i escriptura i llengua oral. S'admet que els processos lector i escriptor no són equivalents, però hi ha aspectes comuns que uneixen l'aprenentatge de la lectura i el de l'escriptura: coneixement dels gèneres discursius, de les estructures gramàtico-discursives que articulen el text, etc.

En aquest marc d'interrelacions es desenvolupa en el moment actual recerca principalment sobre dues d'aquestes interrelacions:

a) Entre lectura i escriptura, defensant que, contràriament al tòpic tradicional que llegint s'aprèn a escriure, es constata que és a través de l'escriptura que s'aprenen moltes de les característiques dels discursos escrits que després permeten comprendre millor com funciona un text escrit que es llegeix.

b) Entre escriptura i coneixement gramatical, que permet avançar en el coneixement de quina gramàtica contribueix al domini del llenguatge escrit i quin model d'ensenyament pot facilitar que els alumnes utilitzin els seus coneixements gramaticals per a la millora dels textos. L'anàlisi de les activitats de revisió, per exemple, en constaten la necessitat.

En aquest article m'he centrat, com he dit al començament, en la recerca sobre ensenyament i aprenentatge de la L1 i la L2. No m'he referit a la recerca sobre ensenyament de la llengua estrangera (LE). Amb això no vull pas dir que no hi hagi interrelació entre unes $\mathrm{i}$ l'altra. Per posar-ne un exemple: des de l'ensenyament de l'anglès com a LE es van constatar les limitacions de les aproximacions comunicatives i es va veure que per superar el que se'n van dir "fossilitzacions" era imprescindible també donar espai a l'ensenyament i 
l'aprenentatge de les formes lingüístiques i dels conceptes que articulen el model gramatical de cada llengua. L'interès de la gramàtica de la L1 en l'aprenentatge de les llengües no és aliena a aquesta necessitat. Per exemple, la llengua escrita té la particularitat que exigeix un control conscient de la producció verbal; també les situacions de bilingüisme social (o de diglòssia) requereixen i propicien una major consciència de les llengües que s'usen fins i tot en la oralitat quotidiana. L'activitat que té com a objecte la llengua que duen a terme els qui parlen o escriuen, és a dir, l'activitat metalingüística, pròpia dels humans és a la base d'aquesta possibilitat de control sobre la producció verbal. Estudiar-la és bàsic per comprendre com es pot desenvolupar l'aprenentatge de la gramàtica.

L'interès pel lloc que ocupa la gramàtica en l'ensenyament de la llengua a tots els nivells és relativament recent en la recerca europea. Al nostre país hi ha dos grups principals que investiguen sobre el tema: el GREAL de la UAB i El GIEL de la Universitat de València. Un dels focus d'atenció principal és, com he dit, l'activitat metalingüística implicada en el coneixement de la llengua i que és a la base del possible aprenentatge gramatical de manera que aquest coneixement contribueixi al domini i a la millora de la producció textual i, per què no? de la comprensió lectora.

Caldria parlar amb major profunditat en els marcs teòric subjacents que han anat fonamentant les diferents recerques al llarg d'aquests períodes, però això requeriria, no una altra conferència, sinó tot un curs sobre la fonamentació de la Didàctica de la llengua i sobre la recerca en aquesta àrea. Només diré que dos paradigmes en certa manera han competit en aquesta fonamentació: un paradigma positivista i un paradigma sociohistòric. La recerca que s'acull a un o a l'altre té sovint objectius diferents. Això advocaria per la necessitat de conjuminar ambdós tipus de recerca, si fos possible.

\section{Referències}

Camps, A. (1994). L'ensenyament de la composició escrita. Barcelona: Barcanova.

Camps, A., \& Milian, M. (coords.) (2008). Mirades i veus. Barcelona: Graó.

Chevellard, Y. (1989). La transposition didactique. Du savoir savant au savoir enseigné (2a. edició revisada , 1991). Paris: La pensée sauvage.

Galí, A. (1928). La mesura objectiva del treball escolar. Quaderns dels cursos lliures de pedagogia. (reedició: Vic: EUMO, 1984). Barcelona: Biblioteca Pedagògica.

Solé, I. (1987). L'ensenyament de la comprensió lectora. Barcelona: CEAC.

\footnotetext{
1 A la UAB l'any 1977, el que se'n deia Secció de filologia va prendre la decisió de independitzar la Didàctica de la llengua i la Literatura de la L1 i la de la L2 que més endavant es va instituir també com assignatura independent.
} 


\begin{abstract}
Biodata de l'autora
Dra Anna Camps és catedràtica emèrita de Didàctica de la Llengua. És mestra, llicenciada en Pedagogia i en Filologia romànica i Doctora en Psicologia. Ha impartit docència en formació inicial i permanent del professorat i en diversos màsters i doctorats. Les seves línies d'investigació prioritàries giren entorn de l'ensenyament de la llengua escrita i de la reflexió metalingüística i l'ensenyament de la gramàtica en els nivells de primària i de secundària. Ha estat investigadora principal de projectes relacionats amb aquests temes $\mathrm{i}$ ha dirigit nombroses tesis doctorals. També ha coordinat i participat en diverses xarxes de grups recerca. Té més de dues-centes publicacions sobre temes de Didàctica de la llengua $i$ sobre recerca $i$ ha impartit conferències en diverses universitats i congressos internacionals. Forma part de l'equip de direcció de la revista "Articles" i és membre dels consells assessors de nombroses revistes sobre lingüística i sobre ensenyament de la llengua i la literatura. E-mail: anna.camps@uab.cat
\end{abstract}

Per citar aquest artícle:

Camps, A. (2017). 25 anys de recerca en didàctica de la llengua. Bellaterra Journal of Teaching \& Learning Language \& Literature, 10(1), 9-19. DOI: http://dx.doi.org/10.5565/rev/jt13.721 